Nicholas B. Sajjadi*, BSc, Ryan Ottwell, DO, Samuel Shepard, BSc, Natasha Bray, DO, Robin Dyer, DO, Jennifer Wilson, DO, Matt Vassar, PhD and Micah Hartwell, PhD

\title{
Assessing the United States' most frequently asked questions about osteopathic medicine, osteopathic education, and osteopathic manipulative treatment
}

https://doi.org/10.1515/jom-2021-0281

Received December 1, 2021; accepted December 15, 2021; published online February 18, 2022

\begin{abstract}
Context: Osteopathic medicine in the United States continues to produce a substantial number of physicians and medical educators. However, recently popularized misconceptions about osteopathic medical practice, education, and manual therapy suggest an unsettling prevalence of inaccurate beliefs held by the public. The public often searches the internet to find out information about osteopathic medicine, but the content of questions and the transparency of the resulting information is unknown.

Objectives: We sought to explore frequently asked questions (FAQs) generated by Google to assess commonly searched questions about the osteopathic profession and to determine the level of information transparency associated with resulting sources.
\end{abstract}

\footnotetext{
*Corresponding author: Nicholas B. Sajjadi, BSc, Office of Medical Student Research, College of Osteopathic Medicine, Oklahoma State University Center for Health Sciences, 1111 W. 17th Street, Tulsa, OK 74107, USA, E-mail: nicholas.sajjadi@okstate.edu

Ryan Ottwell, DO and Samuel Shepard, BSc, Office of Medical Student Research, College of Osteopathic Medicine, Oklahoma State University Center for Health Sciences, Tulsa, OK, USA

Natasha Bray, DO, Robin Dyer, DO and Jennifer Wilson, DO, Office of Medical Student Research, College of Osteopathic Medicine, Oklahoma State University Center for Health Sciences, Tulsa, OK, USA; and Department of Osteopathic Manipulative Medicine, College of Osteopathic Medicine, Oklahoma State University Center for Health Sciences, Tulsa, OK, USA

Matt Vassar, PhD and Micah Hartwell, PhD, Office of Medical Student Research, College of Osteopathic Medicine, Oklahoma State University Center for Health Sciences, Tulsa, OK, USA; and Department of Psychiatry and Behavioral Sciences, College of Osteopathic Medicine, Oklahoma State University Center for Health Sciences, Tulsa, OK, USA
}

Methods: On June 16, 2021, we searched Google for three terms: "osteopathic medicine," "doctor of osteopathic medicine," and "DO," until a minimum of 100 FAQs and their answer links were extracted from each search. After excluding irrelevant FAQs, we used Rothwell's Classification of Questions to categorize the FAQs. We then used the Journal of the American Medical Association's Benchmark Criteria to assess information transparency for each corresponding answer source provided by Google. The answer sources were screened for the inappropriate use of "osteopathy" in place of "osteopathic medicine" and for "osteopath" in place of "DO," "Doctor of Osteopathic Medicine," or "Osteopathic Physician." We performed statistical tests to ascertain the differences in information transparency between osteopathic and nonosteopathic information sources.

Results: Our Google search revealed 110 unique FAQs about osteopathic medicine. The majority of FAQs were classified as fact-based (82/110; 74.55\%), nearly half of which (45.12\%) were related to the medical practicing privileges of DOs. The FAQs were most commonly answered by academic institutions (44/110, 40.0\%). Nearly half $(49.09 \%)$ of the linked answer sources were deemed inadequate by JAMA benchmark criteria. Of the 110 linked answer sources, 19 (17.27\%) misused either osteopathy, osteopath, or both to describe osteopathic physicians. Only 30 sources were linked to US-based osteopathic organizations. Osteopathic organizations were statistically less likely to meet hightransparency criteria than nonosteopathic organizations $(\mathrm{p}=0.002)$.

Conclusions: Our study shows that the US public may be unsure about the physician status of DOs, which may prevent securing the professional identity of osteopathic physicians in the eyes of the public. Osteopathic organizations should tailor awareness campaigns toward addressing the common misconceptions revealed by our study. Osteopathic organizations should use transparency criteria as a rubric when publishing information to enhance transparency. 
Keywords: Doctor of Osteopathic Medicine; medical doctor; medical education; osteopathic manipulative medicine; osteopathic medicine; physician.

Osteopathic medicine in the United States is an established medical discipline responsible for training over $11 \%$ of the active US physician workforce and over $25 \%$ of current US medical students [1]. Osteopathic physicians (DOs), having obtained a Doctor of Osteopathic Medicine degree, are fully licensed to practice medicine and surgery in the United States [2]. DOs work alongside allopathic physicians (MDs) in all major medical specialties, and American residency training programs operate under a single accreditation system for DOs and MDs [3]. DOs, osteopathic residents, and osteopathic medical students are important components of American medical and healthcare systems. As such, maintaining the highest degree of professionalism, competency, and advocacy for the osteopathic profession is an important healthcare objective, because doing so will continue to instill trust among the public, the scientific research community, and most importantly, patient populations.

Previously, we provided evidence of increased internet searches for "osteopathic medicine" in the United States following an unfortunate misrepresentation of the osteopathic profession on national media [4]. The American Osteopathic Association (AOA) responded by launching awareness campaigns to educate the public on osteopathic medicine and DOs and to mitigate potentially negative effects from the poor publicity [5]. Although awareness campaigns are a necessary component of professional advocacy, they do not necessarily address the common conceptions (or misconceptions) held by the US public about DOs, osteopathic medicine, or osteopathic education. Traditional cross-sectional studies, often relying on surveys, are useful for determining such prevalences, but survey studies are subject to certain limitations and biases that limit their utility $[6,7]$. New methods using internet search engine analytics have been devised that afford the ability to obtain cross-sectional information while forgoing many of the limitations of traditional cross-sectional studies [8-10].

In the current study, we sought to use frequently asked questions (FAQs) generated by Google to assess and characterize commonly searched questions about the osteopathic profession in the United States. Additionally, we used an established information transparency assessment tool to examine the information assigned by Google to answer commonly searched questions about osteopathic medicine. Findings from this study will help tailor awareness campaigns by osteopathic organizations toward common questions that, when addressed adequately, are likely to have a considerable positive impact on the awareness of the osteopathic profession. Findings from this study will also inform osteopathic physicians and doctors-in-training with questions that patients or colleagues might have about the profession. We believe that a concerted, evidence-based approach to professional advocacy is necessary to ensure an equitable and informed future for the osteopathic profession.

\section{Methods}

\section{Background}

Google is the most frequently utilized search engine globally, with $92.26 \%$ of the market share in 2021 [11]. Google's search engine is equipped with a robust machine-learning system called RankBrain [12], which is paired with a natural language processing technology called Bidirectional Encoder Representations from Transformers (BERT) to enhance the search engine performance [13]. The two systems work together to uncover search patterns from substantial volumes of search queries. The resulting search patterns are then used to generate lists of the most frequently asked questions related to the original search contents that users can apply to enhance searching. FAQs are listed in "People also ask" boxes or in "Common questions" boxes displayed alongside original search results. Additionally, Google assigns each FAQ a link to information attempting to "answer" each question [14]. As such, Google FAQs are the culmination of potentially millions of common inquiries and the information sources that individuals are likely to encounter when searching Google for information.

The methodology in the current study was originally adapted from a study by Shen et al. [15] that used Google FAQs to examine common concerns regarding orthopedic procedures and to assess the quality of the answer source suggested by Google. The methodology was further improved upon by our research team in a study used to examine commonly held COVID-19 vaccine questions in the United States [8]. We adapted this established methodology to examine the most frequently asked questions regarding osteopathic medicine in the United States.

\section{Systematic search}

On June 16, 2021, using a web browser clear of browsing history, cookies, cached site data, and saved information to minimize personalized advertisements, we searched Google [16] for three terms: "osteopathic medicine," "doctor of osteopathic medicine," and "DO." We selected these terms to capture the most likely general inquiries regarding osteopathic medicine. For each inquiry, we continually refreshed the list of FAQs in the "People also ask" box by clicking on each FAQ tab. Expanding FAQ tabs provides additional FAQs related 
Table 1: Rothwell's classification of questions, question classification by topic, and answer source type.

\begin{tabular}{|c|c|}
\hline Rothwell classification & Description \\
\hline Fact & $\begin{array}{l}\text { Asks objective, factual information regarding DOs, Osteopathic Medicine, or OMT (i.e., How long does } \\
\text { it take to earn a DO degree?) }\end{array}$ \\
\hline Policy & $\begin{array}{l}\text { Asks information on a specific course of action under given circumstances related to DOs, Osteopathic } \\
\text { Medicine, or OMT (i.e., Should I go to a DO or an MD?) }\end{array}$ \\
\hline Value & $\begin{array}{l}\text { Asks to conceptually evaluate DOs, Osteopathic Medicine, or OMT (i.e., Is osteopathic medicine real } \\
\text { science? Are MDs better than DOs?) }\end{array}$ \\
\hline Question subclassification by topic & Description \\
\hline \multicolumn{2}{|l|}{ Fact } \\
\hline Definitions & Questions about the meaning of osteopathic medicine, DO, OMT, etc. \\
\hline Medical practice & $\begin{array}{l}\text { Specific questions about DO practicing privileges, career, profession, specializing, board } \\
\text { certifications }\end{array}$ \\
\hline Medical education/training & Duration of school, competitiveness/prestige of program, acceptance/application process, etc. \\
\hline OMM/OMT & Indications for OMT, how it works, is it covered by insurance, etc. \\
\hline \multicolumn{2}{|l|}{ Policy } \\
\hline Choosing a DO & Who should or should not seek treatment from DOs (i.e., Should I see a DO or an MD?) \\
\hline Seeking OMM/OMT & Questions asking whether person should receive OMT as opposed to another treatment modality \\
\hline \multicolumn{2}{|l|}{ Value } \\
\hline Evaluation of credibility/competency & Seeking authoritative approval from a trustworthy source; seeking Ethos (i.e., Are DOs safe?) \\
\hline $\begin{array}{l}\text { Unique features of osteopathic } \\
\text { medicine }\end{array}$ & $\begin{array}{l}\text { What makes DOs, Osteopathic Medicine, or Osteopathic Education unique? (i.e., Why should I go to an } \\
\text { Osteopathic medical school?) }\end{array}$ \\
\hline Answer source type & Description \\
\hline Commercial & $\begin{array}{l}\text { Organization that publishes medical information that is not otherwise associated with an academic } \\
\text { institution, government agency, healthcare system, or nonmedical news outlet: i.e., WebMD, Healthline }\end{array}$ \\
\hline Academic & $\begin{array}{l}\text { Institution with clear academic affiliations as evidenced by information on the website that did not } \\
\text { better meet criteria for another classification or website ending in “.edu": i.e., Mayo Clinic, Harvard } \\
\text { University }\end{array}$ \\
\hline Medical practice & $\begin{array}{l}\text { Affiliation with a healthcare system or individual healthcare professional that did not explicitly state } \\
\text { commercial, academic, or government affiliation, i.e., Private practice, Hospital system }\end{array}$ \\
\hline Government & Websites hosted by government organizations or sources from websites ending in “.gov.”: i.e., CDC, FDA \\
\hline Media outlet & $\begin{array}{l}\text { Nonmedical organizations or social media pages claiming to publish news-related stories for the purpose } \\
\text { of information sharing in the form of interviews, blog posts, or articles: i.e., NPR, WSJ, USA Today }\end{array}$ \\
\hline
\end{tabular}

CDC, Centers for Disease Control and Prevention; DO, Doctor of Osteopathy; FDA, Food and Drug Administration; NPR, National Public Radio; OMM, osteopathic manipulative medicine; OMT, osteopathic manipulative treatment; WSJ, Wall Street Journal.

to the search query. We repeated this process until reaching a minimum of 100 FAQs for each search. We obtained a minimum of 100 FAQs because previous studies with similar methodology have recommended using $50-150$ sources $[8,15]$.

\section{Data extraction}

Once the predetermined number of FAQs had been reached, we used the Scraper tool [17] to extract FAQs and the associated answer links. In a masked and duplicated fashion using a pilot-tested Google form, authors N.S. and R.O. screened each FAQ for relevance to the search on June 21, 2021. We first removed any duplicate FAQs from the individual searches. Then, we compiled the results of the three searches and screened for relevance pertaining to osteopathic medicine. We excluded any FAQ pertaining to "osteopaths" or "osteopathy," because this profession is common in countries outside of the United States and is distinctly different from osteopathic medicine, osteopathic physicians, and Doctors of Osteopathic Medicine in the United States [18]. FAQs not related to osteopathic medicine were also removed at this stage. After the screening process, our searches resulted in a compilation of unique FAQs about osteopathic medicine in the United States along with associated answer links.

\section{Question classification and answer source type}

Applying methodology adapted from published literature $[8,19,20]$, we first used Rothwell's Classification of Questions [21] to categorize FAQs under three general categories: Fact, Policy, and Value. Fact questions were further subclassified into four groups: Definitions, Practicing Privileges, Medical Education/Training, and Osteopathic Manipulative Treatment (OMT). Policy questions were subclassified into two groups: Choosing a DO; and Seeking OMT. Value questions were subclassified into two groups: Evaluation of Credibility/Competency; and Unique Features of Osteopathic Medicine. Next, we 
Table 2: JAMA benchmark criteria.

\begin{tabular}{ll}
\hline Criteria & Description \\
\hline Authorship & $\begin{array}{l}\text { Clearly identifiable author and contributors with } \\
\text { affiliations and relevant credentials present. } \\
\text { References and sources clearly listed with any } \\
\text { copyright information disclosed. } \\
\text { Currency }\end{array}$ \\
Cisclosure & $\begin{array}{l}\text { as well as date of any revisions. } \\
\text { Website ownership clearly disclosed along } \\
\text { with any sponsorship, advertising, underwriting, } \\
\text { and financial support. }\end{array}$ \\
\hline
\end{tabular}

JAMA, Journal of the American Medical Association.

categorized answer sources as either Commercial, Academic, Medical Practice, Government, or Media Outlet according to previously established classification schemes [15, 22]. Refer to Table 1 for Question Classification and Answer Source Type definitions.

\section{Information transparency}

The Journal of the American Medical Association's (JAMA) Benchmark Criteria [23] was then used to assess information transparency for each answer source. The JAMA Benchmark Criteria has been used to effectively screen online information for fundamental aspects of information transparency [15, 24-26]. Sources meeting three more criteria are considered to have high transparency, whereas sources meeting less than three criteria have poor transparency. Refer to Table 2 for the JAMA Benchmark Criteria definitions.

In addition to extracting FAQs and answer sources, we screened each answer source for the inappropriate use of the terms osteopathy in place of osteopathic medicine and osteopath in place of DO, Doctor of Osteopathic Medicine, or Osteopathic Physician. In 1960, the AOA House of Delegates voted in favor of using "the terms osteopathic medicine in place of the word osteopathy and osteopathic physician and surgeon in place of osteopath; the words osteopathy and osteopath being reserved for historical, sentimental, and informal discussions only" [27, 28]. However, even after this ruling, the degree granted by Colleges of Osteopathic Medicine remained Doctor of Osteopathy. It was not until 1993 when the AOA House of Delegates voted to give osteopathic schools the choice to grant either a Doctor of Osteopathy degree or a Doctor of Osteopathic Medicine degree in an attempt to reduce confusion regarding the equivalency of $\mathrm{DO}$ and MD training [28]. Moreover, the inappropriate use of osteopath and osteopathy poses a threat to the professional identity of DOs, because the term osteopath refers to nonphysician practitioners trained outside of the United States (primarily the United Kingdom and Australia) [29].

Osteopaths perform manual techniques in a fashion reminiscent of chiropractic practitioners in the United States, with many techniques borrowed from traditional OMT developed by US DOs [30]. While this distinction is likely a source of confusion regarding osteopathic physicians in the United States, one thing is certain: osteopaths are not physicians and are not licensed to practice medicine or perform surgery [18]. Likewise, osteopathy is not conventional medicine and does not rest on the foundational principles of physiology, pathology, and pharmacology. Lastly, osteopaths are granted a Diploma of Osteopathy upon completing their training; this is a designation that is often abbreviated as $D O$, deepening the confusion surrounding osteopathic physicians trained in the United States [18]. Since the founder of Osteopathic Medicine, Dr. Andrew Taylor Still [31], referred to the profession as Osteopathy, and in keeping with the AOA ruling of 1960 [27], any sources using these terms to detail the history of the profession were not coded as having inappropriate use. Only sources referring to osteopathic physicians as osteopaths or osteopathic medicine as osteopathy were coded as having inappropriate use. We also documented whether a source was distinctly osteopathic (i.e., AOA, AACOM, The DO, COMs, Journal of Osteopathic Medicine [formerly JAOA]) to examine the incidence of improper use of these terms compared to nonosteopathic answer sources.

All assessments were performed in masked duplicate fashion, with author M.H. resolving any discrepancies. This protocol was submitted to the Oklahoma State University Center for Health Sciences Institutional Review Board and was determined to be non-human subjects research.

\section{Analyses}

Frequencies and percentages were calculated for each FAQ's classification. Chi-square tests were used to assess for associations between the JAMA Benchmark Criteria by source type and whether the sources were osteopathic. Chi-square tests were used to assess for differences in information transparency, the use of incorrect terminology, and whether the sources were osteopathic.

\section{Results}

\section{Search return and FAQ characteristics}

Our Google investigation revealed 110 unique FAQs about osteopathic medicine. These FAQs were linked to answer sources comprised of academic institutions (44/110, 40.0\%), commercial sites (48/110, 43.64\%), government sites $(2 / 110,1.82 \%)$, media outlets $(7 / 110,6.36 \%)$, and medical practices or hospitals $(9 / 110,8.18 \%)$. Of the 110 FAQs, $82(74.55 \%)$ were classified as fact-based, 2 (1.82\%) were policy-based, and 26 (23.64\%) were value-based. Of the fact-based FAQs, 37 (of 82, 45.12\%) were related to medical practice and privileges of DOs, and 24 (of 82, $29.27 \%$ ) were related to osteopathic medical education. Of the 26 Value FAQs, 19 (73.08\%) were inquiring about unique aspects of osteopathic physicians, whereas the other 7 (26.92\%) were questioning credibility or competency. Both policy-based questions were subclassified as Choosing $a \mathrm{DO}$. We have included the list of unique FAQs, their classifications, the associated answer source type, and the JAMA benchmark scores in Supplementary Material. 
Table 3: Associations between information source type and study characteristics.

\begin{tabular}{|c|c|c|c|c|c|c|c|}
\hline & \multicolumn{5}{|c|}{ Source type } & \multirow[t]{2}{*}{ Total } & \multirow{2}{*}{$\begin{array}{l}\text { Statistical test (DF), } \\
\text { p-Value }\end{array}$} \\
\hline & Academic & Commercial & Government & Medical practice & Media outlets & & \\
\hline \multicolumn{8}{|c|}{ JAMA benchmark criteria } \\
\hline Less than 3 & $24(21.82)$ & $24(21.82)$ & $0(0)$ & $0(0)$ & $6(5.45)$ & $54(49.09)$ & $X^{2}(4)=10.3 ; 0.04$ \\
\hline 3 or greater & $20(18.18)$ & $24(21.82)$ & $2(1.82)$ & $7(6.36)$ & $3(2.73)$ & $56(50.91)$ & \\
\hline \multicolumn{8}{|l|}{ Authorship } \\
\hline No & $27(24.55)$ & $23(20.91)$ & $0(0)$ & $0(0)$ & $6(5.45)$ & $56(50.91)$ & $x^{2}(4)=12.32 ; 0.02$ \\
\hline Yes & $17(15.45)$ & $25(22.73)$ & $2(1.82)$ & $7(6.36)$ & $3(2.73)$ & $54(49.09)$ & \\
\hline \multicolumn{8}{|l|}{ Attribution } \\
\hline No & $19(17.27)$ & $13(11.82)$ & $1(0.91)$ & $2(1.82)$ & $3(2.73)$ & $38(34.55)$ & $x^{2}(4)=2.96 ; 0.56$ \\
\hline Yes & $25(22.73)$ & $35(31.82)$ & $1(0.91)$ & $5(4.55)$ & $6(5.45)$ & $72(65.45)$ & \\
\hline \multicolumn{8}{|l|}{ Currency } \\
\hline No & $23(20.91)$ & $22(20)$ & $0(0)$ & $0(0)$ & $7(6.36)$ & $52(47.27)$ & $x^{2}(4)=11.91 ; 0.02$ \\
\hline Yes & $21(19.09)$ & $26(23.64)$ & $2(1.82)$ & $7(6.36)$ & $2(1.82)$ & $58(52.73)$ & \\
\hline \multicolumn{8}{|l|}{ Disclosure } \\
\hline No & $3(2.73)$ & $9(8.18)$ & $0(0)$ & $0(0)$ & $1(0.91)$ & $13(11.82)$ & $x^{2}(4)=4.48 ; 0.35$ \\
\hline Yes & $41(37.27)$ & 39 (35.45) & $2(1.82)$ & $7(6.36)$ & $8(7.27)$ & $97(88.18)$ & \\
\hline \multicolumn{8}{|l|}{ Classification } \\
\hline Fact & $36(32.73)$ & $35(31.82)$ & $2(1.82)$ & $5(4.55)$ & $4(3.64)$ & $82(74.55)$ & $x^{2}(8)=9.18 ; 0.33$ \\
\hline Policy & $0(0)$ & $2(1.82)$ & $0(0)$ & $0(0)$ & $0(0)$ & $2(1.82)$ & \\
\hline Value & $8(7.27)$ & $11(10)$ & $0(0)$ & $2(1.82)$ & $5(4.55)$ & $26(23.64)$ & \\
\hline \multicolumn{8}{|c|}{ Osteopathic distinction } \\
\hline No & $15(13.64)$ & $48(43.64)$ & $2(1.82)$ & $7(6.36)$ & $8(7.27)$ & $80(72.73)$ & $X^{2}(4)=55.67 ;<0.001$ \\
\hline Yes & $29(26.36)$ & $0(0)$ & $0(0)$ & $0(0)$ & $1(0.91)$ & $30(27.27)$ & \\
\hline \multicolumn{8}{|l|}{ Incorrect use } \\
\hline Both & $1(0.91)$ & $5(4.55)$ & $0(0)$ & $0(0)$ & $1(0.91)$ & $7(6.36)$ & $X^{2}(12)=24.06 ; 0.020$ \\
\hline Neither & $42(38.18)$ & $35(31.82)$ & $2(1.82)$ & $7(6.36)$ & $5(4.55)$ & $91(82.73)$ & \\
\hline Osteopath & $0(0)$ & $0(0)$ & $0(0)$ & $0(0)$ & $1(0.91)$ & $1(0.91)$ & \\
\hline Osteopathy & $1(0.91)$ & $8(7.27)$ & $0(0)$ & $0(0)$ & $2(1.82)$ & $11(10)$ & \\
\hline
\end{tabular}

Bold values are statistically significant.

\section{JAMA benchmark criteria by answer sources}

Benchmark criteria were judged to be adequate when three of the four items were met. The field of FAQs was nearly halved, with 50.91\% (56/110) meeting three or more JAMA benchmark criteria and the rest (54/110, 49.09\%) failing to do so. We found statistically significant differences among sources meeting three or more JAMA benchmark criteria $\left(X_{(4)}^{2}=10.3 ; \mathrm{p}=0.04\right)$, with only $33.3 \%$ (2/6) of media outlets and $45 \%$ of academic institutions meeting three or more, compared to $100 \%$ of both government (2/2) and medical practice $(7 / 7)$ sources. Individual JAMA benchmark criteria items that were statistically different between website groupings were Authorship $\left(X^{2}{ }_{(4)}=12.32 ; 0.02\right)$ and Currency $\left(X^{2}(4)=11.91 ; 0.02\right)$ (Table 3$)$.

\section{Osteopathic organizations and incorrect terms usage}

Among all FAQs, 30 (27.27\%) sources were linked to US-based osteopathic organizations. Of the $30 \mathrm{FAQ}$ by osteopathic organizations, only $8(26.67 \%)$ met three or more JAMA benchmark criteria compared to 48 of the 80 $(60.0 \%)$ nonosteopathic organizations $\left(X_{(1)}^{2}=9.70, p=0.002\right)$ (Table 4). Of the 110 FAQs, 19 (17.27\%) misused either osteopathy, osteopath, or both. The FAQs that met three or more JAMA benchmark criteria more misused these terms $(16 / 56$, $28.57 \%$ ) more frequently than those not meeting three or more criteria $(3 / 54,5.56 \%)$, which is a statistically significant finding $\left(X_{(3)}^{2}=13.23, p=0.004\right)$. Only one osteopathic site misused terminology (of $30,3.33 \%$ ), whereas 18 of the 80 (22.5\%) nonosteopathic organization sites did; however, this was not statistically significant $\left(X_{(3)}^{2}=5.80, \mathrm{p}=0.122\right)$ (Table 5).

\section{Discussion}

We found that the majority of questions searched on Google about osteopathic medicine were seeking factual information, specifically regarding the medical practicing privileges of osteopathic physicians. Thus, the questions 
Table 4: Associations between JAMA Benchmark, osteopathic distinction, and incorrect use of terms.

\begin{tabular}{|c|c|c|c|c|}
\hline & \multicolumn{2}{|c|}{ JAMA benchmark } & \multirow[t]{2}{*}{ Total } & \multirow{2}{*}{$\begin{array}{l}\text { Statistical } \\
\text { test (DF), } \\
\text { p-Value }\end{array}$} \\
\hline & $<3$ & $3+$ & & \\
\hline \multicolumn{5}{|c|}{ Osteopathic distinction } \\
\hline No & $32(29.09)$ & $48(43.64)$ & $80(72.73)$ & $\begin{array}{l}x^{2}(1)=9.70 \\
0.002\end{array}$ \\
\hline Yes & $22(20)$ & $8(7.27)$ & $30(27.27)$ & \\
\hline \multicolumn{5}{|l|}{ Incorrect use } \\
\hline Both & $1(0.91)$ & $6(5.45)$ & $7(6.36)$ & $\begin{array}{l}x^{2}(3)=13.23 \\
0.004\end{array}$ \\
\hline Neither & $51(46.36)$ & $40(36.36)$ & $91(82.73)$ & \\
\hline Osteopath & $1(0.91)$ & $0(0)$ & $1(0.91)$ & \\
\hline Osteopathy & $1(0.91)$ & $10(9.09)$ & $11(10)$ & \\
\hline
\end{tabular}

Table 5: Associations between osteopathic distinction and incorrect use of terms.

\begin{tabular}{lrrrl}
\hline & \multicolumn{2}{c}{ Osteopathic distinction } & Total & $\begin{array}{l}\text { Statistical test } \\
\text { (DF), p-Value }\end{array}$ \\
\cline { 2 - 5 } & \multicolumn{1}{c}{ No } & Yes & & \\
\hline $\begin{array}{l}\text { Incorrect use } \\
\text { Both }\end{array}$ & $7(6.36)$ & $0(0)$ & $7(6.36)$ & $X^{2}(3)=5.80$, \\
& & & & 0.12 \\
Neither & $62(56.36)$ & $29(26.36)$ & $91(82.73)$ & \\
Osteopath & $1(0.91)$ & $0(0)$ & $1(0.91)$ & \\
Osteopathy & $10(9.09)$ & $1(0.91)$ & $11(10)$ & \\
\hline
\end{tabular}

consolidated by Google's algorithms suggest that when the US public searches Google about osteopathic medicine, they are most likely inquiring about the practicing rights of DOs. We believe that this is an important finding, because it highlights a fundamental misunderstanding that is, to some significant degree, held by the US public about DOs. Our findings suggest that a portion of the US public may not know that DOs are physicians or "medical doctors." For example, the FAQs from our investigation included asking whether DOs can perform surgery, whether DOs go to medical school, and whether DOs can deliver babies or write prescriptions. Addressing this knowledge deficit is paramount and is superior to any other, because it is impossible to garner trust in DOs as physicians without first establishing their identities as physicians. Moreover, ensuring that the physician status of DOs is well known by the US public will likely have trickle-down effects.

In addition to addressing what our study suggests are the most common questions about DOs, educating the public on the physician status of DOs will remove the grounds from which other, less common questions are raised. Relatively few (23\%) of the FAQs from our search were value-based questions (compared to fact-based, $74.5 \%$ ), many of which were appraising the differences between DO physicians and MD physicians. However, osteopathic advocacy campaigns have focused primarily on these "differences" [32-35], seemingly without having first established that both DOs and MDs are "medical doctors." Further, the clinically significant differences between DOs and MDs, while historically significant, are essentially nonexistent-save the practice of OMT techniques by DO specialists. Norman Gevitz, a historian and professor at Still University, has documented the history of osteopathic medicine as a profession and the many challenges faced in pursuing full practicing rights for DOs. Gevitz has also commented on the persistent dissatisfaction of many osteopathic students and physicians regarding the poor professional recognition of DOs as medical doctors [28, 36]. Although there have been several attempts to address this knowledge disparity, including unsuccessful attempts to change the official title of DOs to include an "M" (significant for "medical," i.e., MD-O, MD-DO, DO-M, etc.), our study suggests that poor public knowledge of the "medical doctor" status of DOs persists. It seems that even after achieving full practicing privileges and after more than a century of advocating for the practice of medicine by osteopathic physicians, we, as a profession, have failed in a major way: we have been fighting for distinction as osteopathic physicians before we have secured recognition as medical doctors in the eyes of the public.

Additionally, we found that, while minimal, there continues to be the inappropriate use of the terms "osteopath" and "osteopathy." For example, a recent article in the New York Times incorrectly referred to DOs as "osteopaths" and incorrectly categorized DOs as practitioners of alternative medicine [37]. In another case of misrepresentation, comedian Hasan Minhaj mischaracterized DOs on national television as being off-brand doctors compared to MDs, further contributing to the confusion of osteopathic professional identity [38]. Unfortunately, osteopathic sources from our study used inaccurate terminology as often as nonosteopathic sources; however, nonosteopathic sources had higher transparency ratings overall compared to osteopathic sources. The poor transparency noted to be statistically associated with osteopathic sources is troublesome and may reduce the perceived credibility of these sources. Ensuring the availability of transparent, high-quality information regarding osteopathic medicine will support stronger professional advocacy. 


\section{Recommendations}

First, we recommend that online advocacy by osteopathic organizations focus awareness campaigns on the equivalence of $\mathrm{DO}$ and $\mathrm{MD}$ training to address the most common question type searched on Google by the US public. Highlighting osteopathic distinction can only be successfully accomplished after establishing practical equivalency and physician status. We believe that the statement "DOs are medical doctors" encompasses the most important message evidenced by this study, and we suggest that osteopathic organizations use this phrase or similar phrases in future advocacy campaigns to combat the leading misconception about DOs. Using the aforementioned phrasing will prevent confusion about the meaning of the MD designation, because it is commonly misinterpreted as meaning "medical doctor" when it stands for "Doctor of Medicine," the degree granted by allopathic medical schools [39]. Likewise, the DO designation represents the degree granted by osteopathic medical schools and does not preclude osteopathic physicians from using the professional title "medical doctor" or "physician." Additionally, the other FAQs from our search can be used to inform the important but less common question about the profession. Second, osteopathic organizations should use the JAMA Benchmark Criteria as a rubric for ensuring online information transparency, because our study found transparency among osteopathic sources to be lacking. Ensuring information quality and transparency are likely to boost the public's confidence in online information about osteopathic medicine, which is vital for instilling trust in the profession. Further, osteopathic organizations were in the minority of information sources and should attempt to increase their online presence. Finally, to avoid confusion and mislabeling, osteopathic organizations need to ensure the correct use of "DO" and "osteopathic physician" as opposed to "osteopath" and "osteopathy."

\section{Strengths and limitations}

Strengths of this study include its methodology, findings, and relevance to the field of osteopathic medicine. Our methodology was adapted from previously published peerreviewed literature and applied to osteopathic medicine for the first time. Using Google's powerful search analytics, we were able to identify over 100 unique questions about osteopathic medicine as a representative sample of questions from the United States, which can be used to support effective awareness campaigns. Our findings are important to the field, because many attacks and misrepresentations of osteopathic medicine have occurred over the last 2 years, and the importance of dismantling misconceptions remains important. Limitations of this study include its limited observation period, subjective nature, and reliance on Google's algorithm. The population will continue to search Google over time, and the generalizability of our study is limited to the time when our search was performed. Categorizing FAQs according to Rothwell's system is somewhat subjective and leaves the potential for overlapping categories. Google may have left out other important questions that are likely being searched, precluding our results from being all-inclusive.

\section{Conclusions}

We found that the US public may be unsure about the physician status of DOs, which may hinder securing the professional identity of osteopathic physicians in the eyes of the public. Osteopathic organizations should tailor awareness campaigns toward addressing the common misconceptions revealed by our study. The term "osteopath" continues to be confusing for the US public, and osteopathic organizations should limit the use of "osteopath" to historical discussions. In conclusion, we offer a sentiment that we believe represents the purpose of this study and if addressed and used by osteopathic leaders and influencers, is likely to have a significant impact on our professional identity: "Osteopathic medicine is not something different, it’s something more."

Acknowledgements: The authors would like to thank Norman Gevitz, PhD, for his considerable contribution to osteopathic medicine, for ensuring the historical accuracy of this manuscript, and for his critical review of its contents. Lastly, we would like to dedicate this work in loving memory of Abbey Renner, a student researcher of our team. Abbey, your OSU family will forever cherish the time and memories we shared with you.

Research funding: None reported.

Author contributions: N.B.S., S.S., M.V., R.O., and M.H. provided substantial contributions to conception and design, acquisition of data, or analysis and interpretation of data; N.B.S., N.B., J.W., and R.D. drafted the article or revised it critically for important intellectual content; all authors gave final approval of the version of the article to be published; and all authors agree to be accountable for all aspects of the work in ensuring that questions related to the accuracy or integrity of any part of the work are appropriately investigated and resolved. 
Competing interests: None reported.

\section{References}

1. American Osteopathic Association. Osteopathic medical profession report; Published January 31, 2018. https://osteopathic.org/about/aoa-statistics/ [Accessed 14 August 2021].

2. U.S. National Library of Medicine. Doctor of osteopathic medicine. https://medlineplus.gov/ency/article/002020.htm [Accessed 14 August 2021].

3. ACGME. Single accreditation system Accreditation Council for Graduate Medical Education (ACGME). https://acgme.org/ Portals/0/PDFs/Nasca-Community/FAQs.pdf [Accessed 14 August 2021].

4. Sajjadi NB, Shepard S. Somebody who does something other than osteopathy. J Osteopath Med 2020;121:25-7.

5. Zafonte RD. Journal of Osteopathic Medicine: a refreshed and refocused publication for our profession. J Osteopath Med 2021; 121:1-3.

6. Limitations of surveys; Published June 23, 2008. http://conflict. Ishtm.ac.uk/page_26.htm [Accessed 14 August 2021].

7. Jones TL, Baxter MAJ, Khanduja V. A quick guide to survey research. Ann R Coll Surg Engl 2013;95:5-7.

8. Sajjadi NB, Shepard S, Ottwell R, Murray K, Chronister J, Hartwell M, et al. Examining the public's most frequently asked questions regarding COVID-19 vaccines using search engine analytics in the United States: observational study. JMIR Infodemiol 2021;1:e28740.

9. Eysenbach G. Infodemiology and infoveillance: framework for an emerging set of public health informatics methods to analyze search, communication and publication behavior on the Internet. J Med Internet Res 2009;11:e11.

10. Mavragani A. Infodemiology and infoveillance: scoping review. J Med Internet Res 2020;22:e16206.

11. Top 10 search engines in the World (2021 update). reliablesoft.net; Published December 15, 2016. https://www. reliablesoft.net/top-10-search-engines-in-the-world/ [Accessed 20 December 2021].

12. Schachinger KA. Complete guide to the Google RankBrain algorithm. Search Eng J 2017. https://www.searchenginejournal. com/google-algorithm-history/rankbrain/\#close.

13. Devlin J, Chang M-W, Lee K, Toutanova K. BERT: pre-training of deep bidirectional transformers for language understanding. arXiv [csCL] 2018. http://arxiv.org/abs/1810.04805.

14. Nayak P. Understanding searches better than ever before. The Keyword Oct 25, 2019. https://blog.google/products/search/ search-language-understanding-bert.

15. Shen TS, Driscoll DA, Islam W, Bovonratwet P, Haas SB, Su EP. Modern internet search analytics and total joint arthroplasty: what are patients asking and reading online? J Arthroplasty 2021; 36:1224-31.

16. Google. http://google.com [Accessed 12 March 2021].

17. dvthn. Scraper 1.7. https://chrome.google.com/webstore/ detail/scraper/mbigbapnjcgaffohmbkdlecaccepngjd?hl=en [Accessed 16 June 2021].

18. American Association of Colleges of Osteopathic Medicine. How are U.S. osteopathic doctors different than those trained abroad. https://www.aacom.org/become-a-doctor/about-osteopathic- medicine/the-difference-between-u-s-trained-osteopathicphysicians-and-osteopaths-trained-abroad- [Accessed 14 August 2021].

19. Kanthawala S, Vermeesch A, Given B, Huh J. Answers to health questions: internet search results versus online health community responses. J Med Internet Res 2016;18:e95.

20. Shen TS, Driscoll DA, Islam W, Bovonratwet P, Haas SB, Su EP. Modern internet search analytics and total joint arthroplasty: what are patients asking and reading online? J Arthroplasty 2021; 36:1224-31.

21. Rothwell J. Mixed company: communicating in small groups and teams, 10th ed. Oxford: Oxford University Press (OUP); 2006.

22. Starman JS, Gettys FK, Capo JA, Fleischli JE, Norton HJ, Karunakar MA. Quality and content of Internet-based information for ten common orthopaedic sports medicine diagnoses. J Bone Joint Surg Am 2010;92:1612-8.

23. Silberg WM, Lundberg GD, Musacchio RA. Assessing, controlling, and assuring the quality of medical information on the internet: Caveant Lector et Viewor-let the reader and viewer beware. JAMA 1997;277:1244-5.

24. Cassidy JT, Baker JF. Orthopaedic patient information on the world wide web: an essential review. J Bone Joint Surg Am 2016; 98:325-38.

25. Kartal A, Kebudi A. Evaluation of the reliability, utility, and quality of information used in total extraperitoneal procedure for inguinal hernia repair videos shared on WebSurg. Cureus 2019; 11:e5566.

26. Corcelles R, Daigle CR, Talamas HR, Brethauer SA, Schauer PR. Assessment of the quality of Internet information on sleeve gastrectomy. Surg Obes Relat Dis 2015;11:539-44.

27. Allen TW. "Osteopathic physician" defines our identity. J Osteopath Med 1993;93:884.

28. Gevitz N. From "doctor of osteopathy" to "doctor of osteopathic medicine": a title change in the push for equality. Int J Osteopath Med 2014;114:486-97.

29. Osteopathy. https://www.nhs.uk/conditions/osteopathy/ [Accessed 20 September 2021].

30. How are U.S. Osteopathic doctors different than those trained abroad. https://www.aacom.org/become-a-doctor/aboutosteopathic-medicine/the-difference-between-u-s-trainedosteopathic-physicians-and-osteopaths-trained-abroad[Accessed 20 September 2021].

31. Andrew Taylor Still University. The museum of osteopathic medicine. https://www.atsu.edu/museum-of-osteopathicmedicine/museum-at-still [Accessed 14 August 2021].

32. DO vs. MD: what's the difference? https://www. bartonassociates.com/blog/whats-the-difference-do-md [Accessed 29 September 2021].

33. Kowarski I. The difference between D.O. and M.D. Degrees. U.S. News \& World Report; Published December 29, 2020. https://www.usnews.com/education/best-graduate-schools/ top-medical-schools/articles/2019-11-07/the-differencebetween-do-and-md-degrees [Accessed 1 December 2021].

34. Philadelphia College of Osteopathic Medicine. What is osteopathic medicine? Philadelphia College of Osteopathic Medicine; Published January 4, 2016. https://www.pcom.edu/ about/what-is-osteopathic-medicine.html [Accessed 1 December 2021]. 
35. Fletcher J. DO vs. MD: differences and what they do. Published February 19, 2020. https://www.medicalnewstoday.com/ articles/do-vs-md [Accessed 1 December 2021].

36. Gevitz N. The transformation of osteopathic medical education. Acad Med 2009;84:701-6.

37. Zraick K. Covid-19 news: nurse shortage forces long island emergency room to close. The New York Times; Published November 22, 2021. https://www.nytimes.com/live/2021/11/22/world/covidvaccine-boosters-mandates [Accessed 24 November 2021].

38. AOA Staff. DOs respond to comments made by Hasan Minhaj on the tonight show; Published October 19, 2021. https://thedo. osteopathic.org/2021/10/dos-fight-back-profession-respondsto-hasan-minhajs-jimmy-fallon-interview/ [Accessed 1 December 2021].

39. Osteopathic medicine: what kind of doctor is a D.O.? Published February 9, 2021. https://www.mayoclinic.org/healthy-lifestyle/ consumer-health/expert-answers/osteopathic-medicine/faq20058168 [Accessed 1 December 2021].

Supplementary Material: The online version of this article offers supplementary material (https://doi.org/10.1515/jom-2021-0281). 